\title{
Prolactin receptor expression by splenocytes from rats in various hormonal states
}

\author{
H. Güneş, S. Z awilla* and A. M. M astro* \\ Department of Biology, Izmir Institute of Technology, Çankaya, Izmir, Turkey and *Department of \\ Biochemistry and Molecular Biology, The Pennsylvania State University, Pennsylvania, USA
}

(Received 7 July 1997; revision accepted 14 July 1997)

\begin{abstract}
Prolactin (PRL) is mitogenic for lymphocytes in vitro, but the responsiveness of lymphocytes depends on the in vivo hormonal status of the rats from which the cells were obtained. Lymphocytes from ovariectomized (OVX) rats, but not from rats in oestrus or from male rats, respond to prolactin; administration of oestradiol to OVX rats diminishes the response. In order to determine if a correlation exists between lymphocyte responsiveness to prolactin and levels of cell surface prolactin receptors (PRL-R) expression, the percentage of splenocytes and each splenocyte subpopulation expressing surface $P R L-R$ from rats of various hormonal states (OVX, oestradiol-injected OVX, oestrus and male) was analysed by singlecolour and dual-colour flow cytometric analysis. We found that approximately $20 \%$ of splenocytes expressed surface PR $L-R$ regardless of hormonal states $(n=16)$. The majority (85\%) of PRL-R positive splenocytes were $B$ lymphocytes whereas $11.1 \%$ and $4.8 \%$ of splenocytes expressing the PRL-R were CD 4 positive $T$-helper $\left(T_{H}\right)$ and CD 8 positive $T$-cytotoxic $\left(T_{C}\right)$ lymphocytes, respectively. B lymphocytes also stained more brightly than $T$ lymphocytes. This distribution of PRL-R expression did not show significant alterations on total splenocytes or $T_{H}$ and $T_{C}$ lymphocytes during various hormonal stages. However, the percentage of $P R L-R$-positive $B$ lymphocytes increased markedly in OVX rats (twofold), compared to rats at oestrus. In summary, no correlation was found between the responsiveness to prolactin as a mitogen and levels of PRL-R expression by lymphocytes from rats at different hormonal states. This result suggests that sex steroid hormones may control prolactin responsiveness of lymphocytes by affecting the signal transduction pathway through PRL-R rather than by altering the level of the cell surface receptor expression.
\end{abstract}

Prolactin (PRL) is a member of a family of polypeptide hormones including growth hormone and placental lactogen which probably arose by duplication of an ancestral gene ( $\mathrm{N}$ iall et al. 1971). PR L affects a variety of physiological processes in vertebrates such as reproduction, lactation, growth and morphogenesis, metabolism, behaviour and immunoregulation (Nicoll $\&$ Bern 1972).

Correspondence: Dr H. Güneş, Department of Biology, Izmir Institute of Technology, Gaziosmapasa Bulv. No. 16, Cankaya 35210, Izmir, Turkey. 
The immunoregulatory function of PRL has been supported by substantial evidence. $P R L$ can affect the immune system in vivo and cells of the immune system in vitro. In vivo, PRL has been reported either to enhance or suppress cellular or humoral immune responses. For example, in adult rats, hypophysectomy or bromocriptine treatment caused a lowered production of antibody and of adjuvant-induced arthritis (Nagy \& Berzci 1978, Bernton et al. 1988). Administration of $P R L$ restored these responses. In addition, in vivo administration of PRL appears to regulate DNA synthesis and expression of the c-myc proto-oncogene in lymphoid tissue of hypophysectomized rats (Berczi et al. 1991).

Evidence from in vitro studies indicates that $P R L$ can affect lymphoid cells directly. A rat lymphoma cell line, $\mathrm{Nb2}$, depends on PRL for proliferation (Tanaka et al. 1980). PRL induces the transcription of growth related genes: c-myc, ODC, hsp-70 and $\beta$-actin in Nb2 cells (Y u-L ee 1990). PRL also can regulate interferon regulatory factor (IR F-1) expression in lymphocytes (Stevens \& Y u-L ee 1992). M ore recent studies indicated that PRL is mitogenic for splenocytes from ovariectomized $(O V X)$ rats (M ukherjee et al. 1990; Viselli \& M astro 1991). Cells from females in oestrus, from OVX rats injected with oestradiol, or from males did not proliferate in response to PRL. H owever, cells from all groups gave similar responses to a polyclonal T-cell mitogen, Con A. From these studies, PRL appears to behave like a classical T-cell mitogen in that it causes IL-2 production and IL-2R expression.

Prolactin exerts its biological effects by binding to its receptor. Prolactin receptor (PRL-R) is encoded by a single gene on chromosome 5. PRL-R CDNA from rat liver and ovary, rabbit mammary gland, human breast, liver tumour cell lines (review by Kelly et al. 1993) and mouse mammary gland (Moore \& Oka 1993) have been cloned and sequenced. Two forms of PRL-R have been identified in normal rat tissues: long and short forms. The short form differs from the long form in length and sequence of the last 30 amino acids in the C-terminal region (B outin et al. 1988, E dery et al. 1989; Shirota et al. 1990). The significance of the existence of two forms of the PRL-R is not known. In addition to the short and the long form, a mutant intermediate form of PRL-R has been found in $\mathrm{Nb2}$ cell line (Ali et al. 1991). This form of PRL-R is missing 198 amino acid region in cytoplasmic domain.

Because $P R L$ is a potent mitogen for splenocytes from $O V X$ rats, we believe that there is a difference in the splenocytes from animals in different hormonal states (OVX, OVX rats injected with oestradiol and oestrus, and male rats). O ne difference may be at the cellular level, i.e. the lymphocyte subpopulation composition may be different or the lymphocytes may express more or different receptors. Therefore, the aim of this study was to investigate how lymphocyte subpopulations and the expression of cell surface PRL-R on lymphocytes change during different hormonal states. Cells treated with antibodies against PRL-R and lymphoid specific surface markers were analysed by flow cytometry.

\section{MATERIALS AND METHODS}

\section{Animals}

Fisher $\mathrm{F} 344$ rats (Charles River, Wilmington, MA) were housed in a room maintained at $20-22^{\circ} \mathrm{C}$ on a $14 \mathrm{~h}$ light, $10 \mathrm{~h}$ dark schedule with free access to food and water. Female rats were ovariectomized $(\mathrm{OVX})$ at 43 days of age. A fter 14 days, OVX rats were sacrificed or injected with 17 - $\beta$-oestradiol in $0.1 \mathrm{ml}$ sesame oil. Two days and 1 day prior to sacrifice, animals were administered $0.5 \mu \mathrm{g}$ and $50 \mu \mathrm{g}$ oestradiol, respectively. Intact females with 4 day regular cycle were sacrificed on the day of oestrus. All oestrus females and male rats were sacrificed between 57 and 75 days of age. 


\section{Lymphocyte preparation}

$\mathrm{R}$ ats were sacrificed by $\mathrm{CO}_{2}$ asphyxiation. Spleens were removed asceptically, placed in dishes in sterile Dulbecco's phosphate buffered saline (PBS), pH 7.2, and gently crushed to release the lymphocytes from the tissue. Cells were passed through fine wire mesh to remove

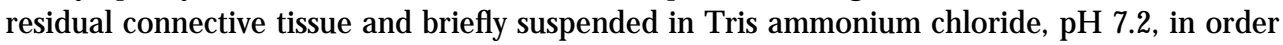
to lyse erythrocytes. Cells were washed in weak, buffered acid ( $25 \mathrm{~mm}$ sodium acetate in PBS, $\mathrm{pH}$ 4) to free any ligands from their cell surface receptor, thereby ensuring that epitopes recognized by antibodies were free from obstruction. Cells were counted using a haemocytometer; viability was determined by trypan-blue exclusion. Viability was $>85 \%$.

\section{Antibodies and staining of splenocytes}

M ouse monoclonal antibodies (IgG 1 isotype) used to stain for specific rat leukocyte antigens were obtained from Bioproducts for Science (Indianapolis, IN). A nti-rat CD 4, anti-rat CD 8, anti-rat CD 5, anti-kappa light chain and anti-IL-2R $\alpha$-chain were used at $1 / 400,1 / 800,1 / 400$, $1 / 800$ and $1 / 400$ final dilutions, respectively, following previously published procedures ( $G$ üneş \& Mastro 1996). All leukocyte surface antigen antibodies were detected by flow cytometry as log integrated green fluorescence (LIGFL) by using rat anti-mouse IgG conjugated to FITC (Jackson Immuno R esearch Laboratories Inc., West Grove, PA) at a dilution of $1 / 100$. Surface PRL-R were detected using the polyclonal antisera (at $1 / 50$ dilution) to the first 13 amino acids in N terminus of rat PRL-R (Hooper et al. 1993), a gift from D r K urt Ebner (U niversity of K ansas, Medical Center). Cells expressing PRL-R were detected as log integrated yellow fluorescence (LIYFL) by using goat anti-rabbit IgG conjugated to PE (Caltag Laboratories, San Francisco, CA) at a dilution of $1 / 100$. Control antibodies were used to determine background fluorescence and non-specific binding of antibodies. M ouse IgG specific for bovine CD 8, an isotype control with irrelevant specificity served as a control for leukocyte surface antigens. Cells exhibited $1 \%$ to $3 \%$ non-immune staining. Cells incubated with normal rabbit serum (NRS), which served as a control for PRL-R antibody, exhibited $2 \%$ to $5 \%$ non-immune staining. These background values were substructed from experimental values.

Freshly isolated splenocytes were plated at $1 \times 10^{6}$ cells/well in 96 -well v-bottom plates. In dual staining experiments, $50 \mu \mathrm{l}$ of anti-rat leukocyte surface antigen antibody and $50 \mu \mathrm{l}$ of anti-PRL-R antibody were added concurrently to the wells. Cells were incubated at $4^{\circ} \mathrm{C}$ for $25 \mathrm{~min}$ and washed twice with PBS (pH 7.2) containing $2 \%$ calf serum, $1 \%$ goat serum, and $0.01 \%$ azide. Next, $100 \mu$ lappropriate secondary antibodies conjugated to either FITC or PE were added and incubated with the cells for $25 \mathrm{~min}$ in the dark. Cells were washed twice, placed in $100 \mu$ l of fixative ( $1 \%$ paraformaldehyde dissolved in PBS) and stored up to 5 days at $4 \%$ in the dark before the flow cytometric analysis. Prior to analysis, cells were washed three times to remove residual fixative.

\section{Flow cytometric analysis}

Flow cytometric analysis were carried out as described by Viselli \& M astro (1993). Briefly, 10000 cells per sample were analysed in duplicate by an E PICS 753 Flow Cytometer (Coulter Electronics, Hialeah, FL) equipped with two argon ion lasers. The filters used were a 457-504 nm laser blocking filter and a $550 \mathrm{~nm}$ long pass dichronic filter with a $525 \mathrm{~nm}$ band pass filter for FITC fluorescence and $575 \mathrm{~nm}$ band pass filter for PE fluorescence. The laser was tuned to $488 \mathrm{~nm}$ at $100 \mathrm{~mW}$ of power. During data collection, forward angle light scatter and $90^{\circ}$ light scatter was used to gate on cells to be included in analysis; data were collected 
in list mode format. For dual-colour experiments, the four quadrants for analysis were defined using positive control samples with both FITC and PE.

Data was analysed using the Epics Elite software package. Log integrated fluorescence distributions were generated and analysed to determine percentages of cells that were positively fluorescent. In dual-colour experiments, dot plots with log intensity yellow fluorescence as the vertical axes and log intensity green fluorescence as horizontal axes were created. Duplicate samples were averaged. The percentages of positive cells from proper control samples, exhibiting non-immune fluorescence, were substracted from the percentages of positive cells. The Macintosh StatV iew SE + program was used to determine mean values \pm SEM. StatV iew, Fisher PLSD test, was used and significant differences at $95 \%$ $(P=0.05)$ and $99 \%(P=0.008)$ confidence intervals were determined.

\section{RESU LTS}

\section{PRL -R expression by splenocytes}

Cell surface expression of PR L-R was seen on rat splenocytes with antibodies to extracellular region of $P R L-R$ along with flow cytometry. A pproximately $20.6 \pm 2 \%$ (mean $\pm S E M ; n=16$ ) of splenocytes expressed PR $L-R$ regardless of the hormonal states of the animals from which the spleens were taken. The log intensity fluorescence distribution indicated that most of the PRL-R positive lymphocytes stained relatively dimly compared to the highly fluorescent peaks obtained from the fluorescence distribution of CD 4 positive and CD 8 positive lymphocytes (Figure 1a-c).

Because splenocyte preparations contain heterogeneous subpopulations of lymphocytes, we identified some of these cells. Splenocytes were stained with anti-CD 4 for helper T-cells $\left(T_{H}\right)$, anti-CD 8 for cytotoxic T-cells $\left(T_{C}\right)$ and anti-kappa light chain for B-cells. Flow cytometric analysis showed that the percentage of each lymphocyte subpopulation in total splenocytes was $24.3 \pm 0.8 \% \mathrm{CD} 4+; 19.5 \pm 0.7 \% \mathrm{CD} 8+$; and $55.5 \pm 0.9 \%$ B-cells (mean $\pm \mathrm{SEM} ; \mathrm{n}=16$, Table 1).

\section{Percentages of lymphocyte subpopulations expressing PRL -R}

Dual-colour flow cytometric analysis revealed that a greater portion of $B$ lymphocytes expressed surface PRL-R (mean, $31.5 \pm 3 \% ; n=16$ ) compared to either CD $4+$ cells (mean, $9.8 \pm 1.4 \% ; n=16$ of CD $4+$ cells) or CD $8+$ cells $(5.4 \pm 1.2 \%$ of CD $8+$ cells). In other words, the average percentage distributions of B-cells, CD $4+$ cells and CD $8+$ cells among PRL-R positive splenocytes were approximately $85 \%, 11 \%$ and $4.3 \%$, respectively (Table 1 ). This distribution of PRL-R expression among splenocyte subpopulations may be due to the observation that the numbers of $B$ lymphocytes in the spleen outnumber both $T$ lymphocyte subpopulations.

When fluorescence distributions of $P R L-R$ expression in each subpopulations were compared, $B$ lymphocytes stained more brightly for $P R L-R$ than the $T$ lymphocytes (Figure $2 a-c)$. The brightly stained PRL-R positive $B$ lymphocytes were more fluorescent than $P R L-R$ positive $T$-cells. The results indicate that more $B$-cells than $T$ lymphocytes expressed $P R L-R$, and that $B$ lymphocytes also expressed the $P R L-R$ more densely.

\section{PRL -R expression by splenic lymphocytes from rats at various hormonal stages}

In order to determine if responsiveness to $P R L$ as a mitogen in vitro was related to the percentages of splenocytes expressing PRL-R, splenocytes from rats at different hormonal states were subjected to a single-colour and dual-colour flow cytometric analysis. OVX rats, 
oestradiol-injected OVX rats, intact females at oestrus and males were compared. The average percentage of splenocytes expressing PRL-R from oestrus females was lower than that of splenocytes from other groups of rats (Table 2). However, there were no significant differences in the percentages of cells expressing PR L-R from animals in the various physiological stages examined.

M oreover, the percentage of each lymphocyte subpopulation expressing $P R L-R$ was also investigated in rats at various hormonal states, CD 4+, CD $8+$ and $B$ lymphocytes of splenocytes from each group were analysed. A lthough there were no statistically significant differences in the percentage of each lymphocyte subpopulation expressing $P R L-R$ during different hormonal states, the percentage of $B$ lymphocytes expressing surface $P R L-R$ from

(a)

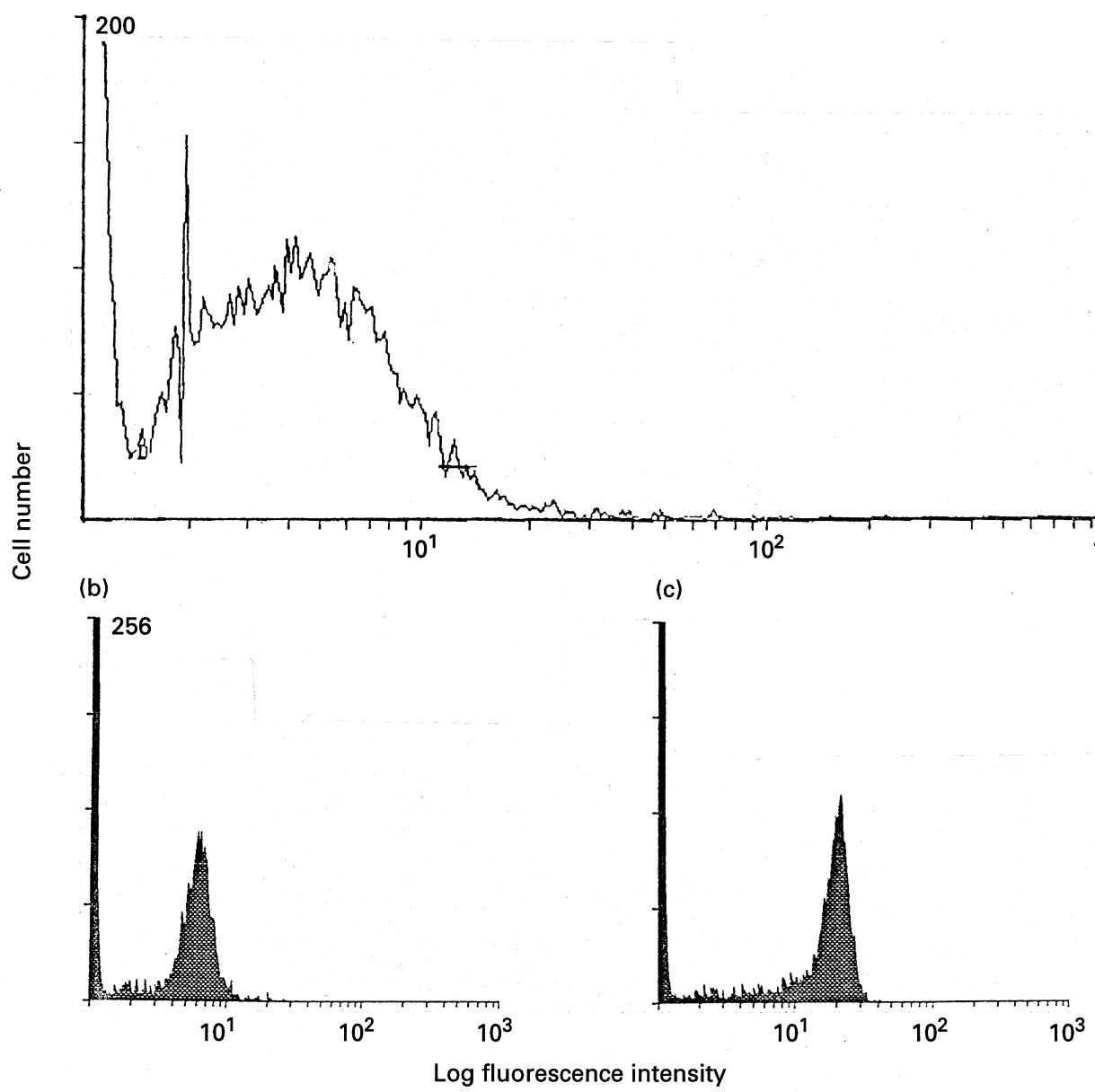

Figure 1. Fluorescent distribution of splenocytes stained with antibodies against PR L-R, CD 4, or CD 8 and FITC-conjugated secondary antibody. Histograms show the log integrated green fluorescence intensity vs. cell size. The average percentages of PRL-R + (a), CD4+ (b) or CD8+ (c) cells are represented in Table 1. 
Table 1. Surface PRL-R expression on subpopulations of splenic lymphocytes

\begin{tabular}{lccc}
\hline $\begin{array}{l}\text { Subpopulations of } \\
\text { splenocytes }\end{array}$ & $\begin{array}{c}\text { Percentage of } \\
\text { total lymphocytes }\end{array}$ & $\begin{array}{c}\text { Percentage of each } \\
\text { subpopulation } \\
\text { expressing PR } L-R\end{array}$ & $\begin{array}{r}\text { R elative brightness } \\
\text { of PRL-R expression }\end{array}$ \\
\hline CD 4+ $\left(T_{H}\right)$ & $24.3 \pm 0.80$ & $9.8 \pm 1.4$ & Low \\
$C D 8+\left(T_{C}\right)$ & $19.5 \pm 0.7$ & $5.4 \pm 1.2$ & Low \\
Slg $+(B)$ & $55.5 \pm 0.9$ & $31.5 \pm 3.1$ & High \\
\hline
\end{tabular}

The percentages of splenocyte subpopulations expressing surface $P R L-R$ was determined by dualcolour flow cytometric analysis. Splenocytes were isolated from rats at different hormonal states and stained with PRL-R antisera and either anti-CD 4, anti-CD 8, or anti-kappa light chain (specific for $T_{H}$, $T_{C}$ and $B$ lymphocytes, respectively). The PRL-R was detected using PE conjugated anti-rabbit IgG antibody, and the splenocyte subpopulations with FITC conjugated anti-mouse IgG antibody. The relative brightness of PRL-R staining was gauged by the positions of cells in the second quadrant along the yellow fluorescence intensity axis of dual-colour dot plots. Data represent the mean \pm SEM $(n=16)$.

OVX rats was significantly greater (mean $40.3 \pm 5 \% ; n=6$ ) than that of $B$ lymphocytes from rats in oestrus (mean $20.1 \pm 3.8 \% ; n=4$ ). In addition, a number of differences among rats from different hormonal backgrounds were observed in the percentages of three lymphocyte subpopulations in the spleen (Table 2). Male rats had a greater percentage of CD4+ lymphocytes (mean $27 \pm 2 \% ; n=3$ ) than OVX (mean $23.1 \pm 0.3 \% ; n=6$ ) or OVX +E 2 rats (mean $21.4 \pm 2.3 \% ; n=3$ ); fewer CD $8+$ cells (mean $16.8 \pm 2 \% ; n=3$ ) than oestrus females (mean $22.0 \pm 1.5 \% ; n=4$ ) more B lymphocytes (mean $59.6 \pm 2.9 \% ; n=3$ ) than either OVX or oestrus females (mean $54.3 \pm 0.9 \% ; n=6$; and mean $52.5 \pm 0.9 \% ; n=4$, respectively). Females in oestrus were observed to have a greater percentage of CD4+ lymphocytes (mean $26.5 \pm 1.2 \% ; \mathrm{n}=4$ ) than $\mathrm{OVX}$ rats (mean $23.1 \pm 0.3 \% ; \mathrm{n}=6$ ) or $\mathrm{OVX}+\mathrm{E} 2$ rats (mean $21.6 \pm 3.9 ; n=3)$; fewer B lymphocytes (mean $52.5 \pm 0.9 \% ; n=4)$ than OVX +E $2(57.9 \pm 1.4 \%$; $\mathrm{n}=3$ ) or male rats (mean $59.6 \pm 2.9 \% ; n=3$ ).

\section{DISCUSSION}

In this study, we investigated how percentages of splenocyte subpopulations and the percentage of each subpopulation expressing $P R L-R$ alter during various hormonal stages in order to determine if a change in these parameters may be responsible for the $P R L$ responsiveness of splenocytes from OVX rats. We found that approximately $24 \%, 20 \%$ and $56 \%$ of splenocytes were CD 4+, CD $8+$ and B lymphocytes, respectively. When the percentage of each splenocyte subpopulation from rats at different hormonal states was compared, a few significant alterations have been observed. First, the percentage of CD $4+$ cells from OVX rats or from $\mathrm{OVX}+\mathrm{E} 2$ rats were significantly less than that of CD $4+$ cells from oestrus rats or from male rats (Table 2). Second, the percentage of CD $8+$ cells from rats at oestrus was statistically greater than that of CD $8+$ cells from male rats. Finally, the percentage of B-cells from male rats was higher than that of $B$-cells from rats at oestrus or from $O V X$ rats. These results indicate that there was no significant alteration in the percentage of CD $8+$ cells and $B$-cells between rats at oestrus and OVX rats. Based on this finding, we concluded that the $P R L$ responsiveness of splenocytes from OVX rats but not from rats at oestrus is not due to the alteration of the percentage of lymphocyte subsets, suggesting that a more subtle difference must exist between PRL-responsive and PRL-unresponsive splenocytes. Furthermore, it seems that a significant decrease in the percentage of CD $4+$ cells in $O V X$ rats compared to 
rats at oestrus may not be one of the possibilities for PRL-responsiveness of Iymphocytes because the percentage of CD $4+$ cells from $O V X+E 2$ was similar to that of CD $4+$ cells in OVX rats.

A few studies have examined the distribution of surface PR L-R on lymphocyte subpopulations from rats at different hormonal stages. Therefore, we firstly determined the percentage of each splenocyte subset expressing PR L-R, regardless of in vivo hormonal states of the rats.

(a)

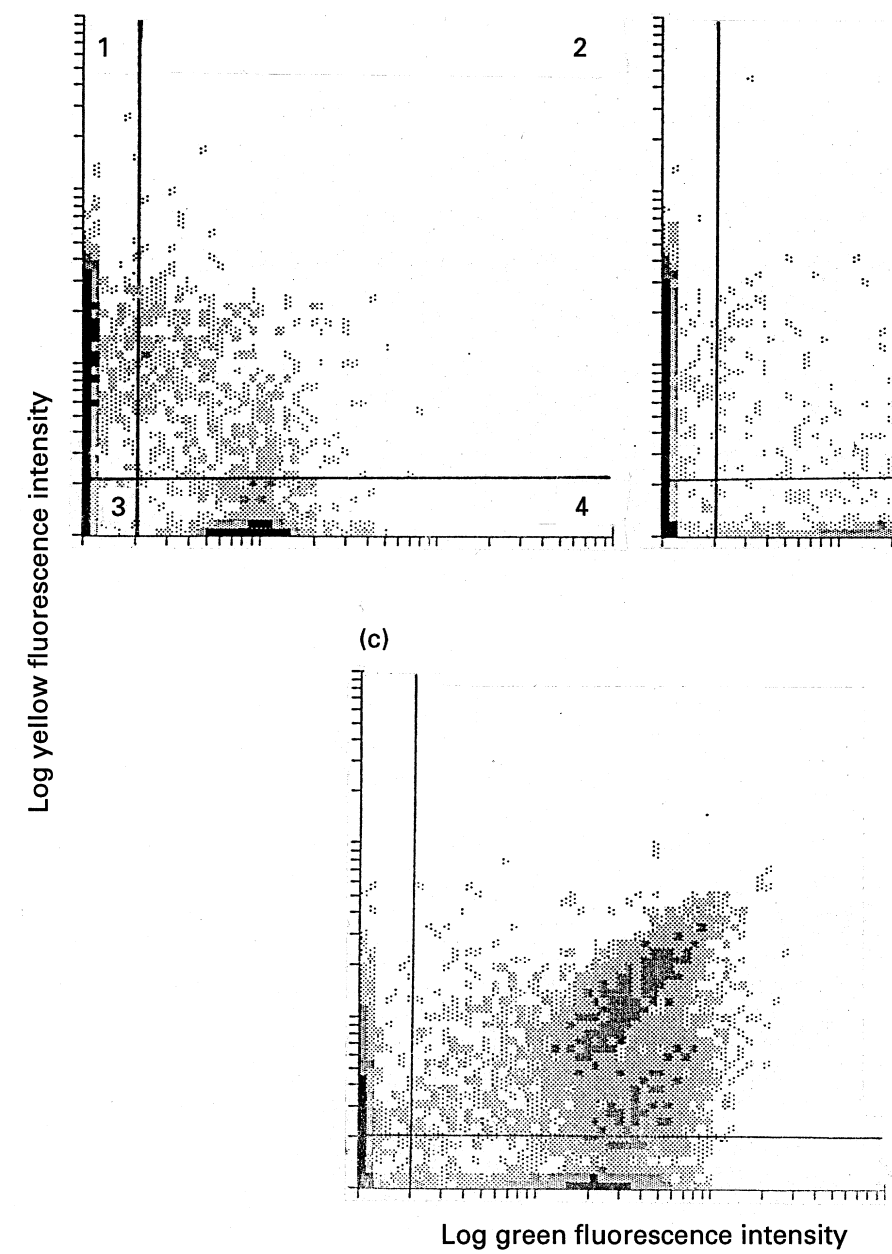

Figure 2. Dual-colour fluorescence dot plot demonstrating the surface membrane expression of $P R L-R$ on CD 4 + (a), CD 8 + (b) or B - (c) cells. Splenocytes were stained with PR L-R antisera and either antiCD 4, anti-CD 8, or anti-kappa light chain. PR L-R positive cells are represented by a log yellow fluorescence intensity distribution. CD 4+, CD 8+ or kappa light chain + cells are represented by a log green fluorescence intensity distribution. Q uadrants 1 and 2 contain cells expressing surface PR L-R ; quadrants 2 and 4 contain cells expressing leukocyte surface antigen being considered; quadrant 2 contains a particular phenotype (e.g. CD4+T-cells) expressing surface PRL-R. A verage percentages $(n=16$, mean \pm SEM) of cells in the dot plot quadrants are represented in the Table 1 . 
Table 2. Percentages of splenocytes expressing PR L-R and their distribution among splenic lymphocyte subpopulations in rat at various hormonal stages

\begin{tabular}{|c|c|c|c|c|}
\hline \multirow{2}{*}{$\begin{array}{l}\text { Splenocyte } \\
\text { phenotype }\end{array}$} & \multicolumn{4}{|c|}{ Hormonal stages } \\
\hline & $O V X$ & $\mathrm{OVX}+\mathrm{E} 2$ & O estrus & M ale \\
\hline PRL-R + (total splenocytes) & $25.0 \pm 4.7$ & $21.6 \pm 3.9$ & $13.6 \pm 4.1$ & $20.3 \pm 3.0$ \\
\hline $\mathrm{T}_{\mathrm{H}}$ cells $(\mathrm{CD} 4+)$ & $23.1 \pm 0.3$ & $21.4 \pm 2.3$ & $26.5 \pm 1.2^{*}$ & $27.1 \pm 2.0^{*}$ \\
\hline$T_{H}$ cells expressing PR L-R (\%) & $11.2 \pm 3.1$ & $12.7 \pm 1.2$ & $6.1 \pm 2.0$ & $8.8 \pm 1.8$ \\
\hline$T_{c}$ cells $(C D 8+)$ & $19.9 \pm 0.4$ & $18.7 \pm 1.4$ & $22.0 \pm 1.5 \dagger$ & $16.8 \pm 2.0$ \\
\hline $\mathrm{T}_{\mathrm{C}}$ cells expressing PRL-R $(\%)$ & $5.3 \pm 1.1$ & $2.1 \pm 1.2$ & $4.5 \pm 2.2$ & $4.4 \pm 0.9$ \\
\hline B-cells (kappa+) & $54.3 \pm 0.9$ & $57.9 \pm 1.4$ & $52.5 \pm 0.9 \ddagger$ & $59.6 \pm 2.9 \S$ \\
\hline B-cells expressing PRL-R (\%) & $40.3 \pm 5.59$ & $29.2 \pm 6.6$ & $20.1 \pm 3.8$ & $30.2 \pm 0.9$ \\
\hline
\end{tabular}

Splenocytes were isolated from rats in different hormonal stages, OVX rats $(n=6)$, OVX rats administered oestradiol (OVX $+E 2 ; n=3)$, females in oestrus $(n=4)$, and males $(n=3)$. The splenocytes were stained and analysed with dual-colour flow cytometry as in the legend to Table 1. Statistical analysis was done using the Fisher PLSD test, and differences at a confidence level of $95 \%$ were considered significant. Data represent the mean \pm SEM. The significant differences among groups were shown by different letters. *D ifferent from $O V X$ and $O V X+E 2$; †different from male; $\ddagger$ different from $\mathrm{OVX}+\mathrm{E} 2$ and male; §different from OVX and oestrus; and Idifferent from oestrus.

Our results show that $10 \%$ of $C D 4+, 5 \%$ of $C D 8+$ and $30 \%$ of $B$ splenocytes express surface PRL-R, and that the majority $(85 \%)$ of total splenocytes expressing $P R L-R$ are $B$ lymphocytes. Similarly, Gagnerault et al. (1993) reported that nearly all B lymphocytes express PRL-R and approximately $95 \%$ of B-cells stain brightly for the receptor by using biotinylated anti-PRL-R monoclonal antibody U 5. They also found that approximately $50 \%$ of $C D 4+$ and $C D 8+$ lymphocytes express PR $L-R$ and most of these cells stain dimly for the receptor. Gala \& Shevach (1993) indicated that $5 \%$ of CD $4+, 20 \%$ of CD $8+$ and $20 \%$ to $80 \%$ of $B$ lymphocytes express surface PRL-R by using the five monoclonal antibodies to $P R L-R$, directly conjugated to fluorescein (Okamura et al. 1989). Viselli \& M astro (1993) reported a much more even distribution of $P R L-R$ among splenocyte subpopulations using a polyclonal antibody, anti-PRL (Bajpai et al. 1991). They found that approximately $25 \%$ of CD $4+$ cells, $25 \%$ of CD $8+$ cells and $20 \%$ of $B$-cells displayed PR L-R. The variability in the percentage of $B$ or $T$ lymphocytes staining positive for $P R L-R$ among these reports is most probably due to different monoclonal or polyclonal antibodies to $P R L-R$, different species and sensitivity of the techniques used in these studies.

In the present study, the percentage of CD $4+$ and CD $8+$ lymphocytes expressing PRL $-R$ did not exhibit a significant change during different hormonal states. Based on the result of $V$ iselli (1992), T-cells but not B lymphocytes proliferated after stimulation with PRL. Therefore, our finding indicates that there is no correlation between responsiveness to $P R L$ as a mitogen for lymphocytes and levels of surface PRL-R expression. This result is in agreement with that of $\mathrm{G}$ ala $\&$ Shevach (1993) who examined the percentage of lymphocyte subsets from intact and $O V X B A L B / C$ mice and found that the percentage of lymphocyte subsets (CD 4+, CD 8+, B-cells) expressing PRL-R did not markedly change in OVX mice. $U$ nlike their findings, we observed that the percentage of $B$ lymphocytes expressing $P R L-R$ was the greatest in the OVX rats compared to intact females in oestrus (Table 2).

Both the present study and the studies of others (V iselli \& M astro 1993, Gagnerault et al. 1993, Gala \& Shevach 1993) indicate that B lymphocytes display cell surface PR L-R . A mong the lymphocyte subsets expressing surface $P R L-R$, the percentage of $B$ lymphocytes is higher 
than that of $C D 4+$ and $C D 8+$ lymphocytes. However, the role of PRL in regulating the activity of each splenocyte subset is not known yet. When splenocytes are stimulated with $P R L$ and stained for DNA content with propodium iodide, the CD $4+$ and CD $8+$ lymphocytes but not $B$ lymphocytes move beyond $G_{0} / G_{1}$ and increase in $D N A$ content (V iselli 1992). A fter $96 \mathrm{~h}$ of stimulation with PRL, the percentages of CD $4+$ and CD $8+$ lymphocytes in culture increased significantly (V iselli \& M astro 1991). Gala \& Shevach (1993) observed that in ConA stimulated cultures, the $T$ lymphocytes increase their surface membrane expression of PRL-R but B lymphocytes do not. In addition, in ConA stimulated lymphocyte cultures, a molecule with prolactin-like bioactivity is secreted (M ontgomery et al. 1987). Because ConA is a T-cell mitogen, it was proposed that T-cells secreted the PR L. In a further study, $T$-cells separated from ConA stimulated cultures were shown to express PRL mRNA. These data give some clue about the prolactin's role in regulation of the $T$ lymphocyte activity but they do not explain why B lymphocytes express PR L-R. H artmann et al. (1989) demonstrated that the antisera to prolactin can abrogate the mitogenic response of lymphocytes to both ConA and the B-cell mitogen, lipopolysaccharide. Therefore, prolactin appears to have a role in regulating $B$-cell, as well as $T$-cell, proliferation. $H$ owever, more experiments need to be carried out to elucidate the role of prolactin in the $B$ lymphocytes.

$\mathrm{H}$ ow responsiveness to $\mathrm{PRL}$ is linked to the hormonal status of the rat is still unknown but there are possibilities that need to be examined in future studies. For example, Guillaumot \& Cohen (1994) reported that depending on the various physiological stages of the rats, different molecular forms of PRL-R were observed by ${ }^{125} \mathrm{I}-\mathrm{OPR} L$ binding studies. Therefore, it could be possible that during different hormonal states, a certain molecular form of PRL $-R$ may appear in the spleen and transduce the mitogenic signal of $P R L$ to splenocytes. In addition, antibody to the long form of PR $L-R$ recognized two different molecular forms (42 $\mathrm{kDa}$ and $84 \mathrm{kDa}$ ) of PRL-R in the spleen ( $\mathrm{G}$ üneş \& M astro 1996), and ovariectomy may cause differential expression of these two molecular forms of the receptor. In further studies, ${ }^{125}$ I-OPR L binding experiments as well as W estern blot analysis might distinguish among these possibilities.

Both long and short forms of the PRL-R are expressed in the rat. The long form of $P R L-R$ is capable of transducing signal for induction of milk gene expression when transfected into Chinese hamster ovary cells whereas the short form does not (Ali et al. 1992). Therefore, it is likely that these receptors function differently. If this is the case, the circulating steroid hormones could control the expression of both forms of the PRL-R, and responsiveness to $P R L$ as a mitogen would correlate to predominantly expressed form of the receptor. Indeed, ovariectomy resulted in a decrease in $\mathrm{mRNA}$ levels of both short and long forms of the PRL-R in rat brain (Sugiyama et al. 1994). Because effect of hormones on the expression of forms of PRL-R may be tissue specific (G üneş 1995), ovariectomy could possibly exhibit more different effects on the expression level of long and short forms of $P R L-R$ in spleen than it does in the brain.

A Iternatively the level of $P R L-R$ expression may not be correlated to $P R L$ responsiveness of splenocytes at all. R ecent studies have indicated an association between each $P R L-R$ isoform and a src family protein thyrosine kinase ( $p 59^{\mathrm{fyn}}$ ) in NB2 cells (Clevenger \& M edaglia 1994). Prolactin stimulation resulted in activation of fyn and proliferation of NB2 cells. In addition, JAK family tyrosine kinase JAK 2 have been shown to be associated with PRL-R ( $R$ ui et al. 1994). However, the function of these protein thyrosine kinases in signal transduction pathway through PRL-R in order to stimulate lymphocytes to divide is not yet well known. Therefore, it is possible that the key to whether lymphocytes are responsive or unresponsive to prolactin as a mitogen lies within the signal transducing network in the cell. 
Perhaps circulating steroid hormones could preside over whether or not the signal to divide is transduced to the nucleus. Elucidation of signal transduction pathway through PRL-R may help us understand how hormones affect signal transduction for lymphocyte proliferation upon stimulation with PRL.

In conclusion, the hormonal status of the animal can influence PR L-R expression. Specifically a greater percentage of $B$ lymphocytes express PRL-R in OVX rats than rats at oestrus. $H$ owever, no correlation was found between the responsiveness to $P R L$ as a mitogen and the levels of cell surface PR L-R expression by lymphocytes during different hormonal stages. The underlying mechanism for the initial observation that $P R L$ serves as a mitogen for lymphocytes in vitro only in rats of certain hormonal backgrounds has yet to be determined. Research to elucidate the signal transduction pathway by PRL-R and how sex steroid hormones modulate the signal transduction by PRL-R may reveal the mechanism. Nevertheless, the finding that PRL-R expression can be modulated by hormonal status gives us clues for future investigations.

\section{A CKNOWLEDGEMENTS}

The authors are grateful for the flow cytometry expertise of Elain Kunze.

\section{REFERENCES}

Ali S, Pelligrini I, Kelly PA. (1991) A prolactin dependent immune cell line (Nb2) expresses a mutant form of prolactin receptor. J. Biol. Chem. 266, 20110.

Ali S, Edery M, Pellegrini I et al. The Nb2 form of prolactin receptor is able to activate a milk protein gene promoter. Mol. Endocrinol. 1242, 1248.

Bajpal A, Hooper KP, EBner KE. (1991) Interactions of antisense peptides with ivine prolactin. Biochem. Biophys. Res. Commun. 180, 1312.

Berczi I, Nagy E, Toledo SM, Matusik RJ, Friesen HG. (1991) Pituitary hormones regulate c-myc and DNA synthesis in lymphoid tissue. J. Immunol. 146, 2201.

Bernton EW, Meltzer MS, Holaday JW. (1988) Suppression of macrophage activation and T-lymphocyte function in hypoprolactinemic mice. Science 239, 404.

Boutin J m, J olicoer C, OkAmura H et al. (1988) Cloning and expression of the rat prolactin receptor, a member of the growth hormone/prolactin receptor gene family. Cell 53, 69.

Clevenger CV, Medaglia MV . (1994) The protein tyrosine kinase p59 fyn is associated with prolactin receptor and is activated by prolactin stimulation of T-lymphocytes. Mol. Endocrinol. 8, 674.

Edery M, Jolicoer C, Levi Meyrueis C et al. (1989) Identification and sequence analysis of a second form of prolactin receptor by molecular cloning of CDNA from rabbit mammary gland. Proc. Natl. Acad. Sci. USA 86, 2112.

Gagnerault M, Touraine P, Savino W, Kelly PA, Dardenne M. (1993) Expression of prolactin receptors in murine lymphoid cells in normal and autoimmune situations. J. Immunol. 150, 5673.

Gala RR, Shevach EM. (1993) Identification by analytical flow cytometry of prolactin receptors on immunocompetent cell populations in the mouse. Endocrinol. 133, 1617.

Guillaumot P, Cohen H. (1994) Heterogeneity of the prolactin receptor in the rat mammary gland and liver during various physiological states. J. Endocrinol. 141, 271.

GüNEŞ H. (1995) The expression of forms of prolactin receptor in splenic and thymic tissues of rats at different developmental and physiological stages. Submitted in partial fulfillment of the requirements for the degree of PhD at The Pennsylvania State U niversity.

Güneş H, Mastro AM. (1996) Prolactin receptor gene expression in rat splenocytes and thymocytes from birth to adulthood. Mol. Cell. Endocrinol. 117, 41.

Hartmann DP, Holaday JW, Bernton EW (1989) Inhibition of lymphocyte proliferation by antibodies to prolactin. FASE B 3, 2194.

Kelly PA, A LI S, R ozAkIS M et al. (1993) The growth hormone/prolactin receptor family. Rec. Progress Hor. Res. 48, 123. 
Montgomery DW, Zuloski CF, Shah GN, Buckley AR, Pacholczyk T, Russell Dh. (1987) Concanavalin-A stimulated murine splenocytes produce a factor with prolactin-like bioactivity and immunoreactivity. Biochem. Biophys. Res. Commun. 145, 692.

MOORE RC, OKA T. (1993) Cloning and the sequencing of the CDNA encoding the murine mammary gland long-form prolactin receptor. Gene 134, 263.

Mukherjee P, Mastro AM, Hymer WC. (1990) Prolactin induction of interleukin-2 receptors on rat splenic lymphocytes. Endocrinol. 126, 88.

NAGY E, BerczI I. (1978) Immunodeficiency in hypophysectomized rats. Acta. Endocrinol. 89, 530.

Niall hD, Hogan ML, Sayer R, Rosenblum IY, Greenwood IC. (1971) Sequences of pituitary and placental lactogenic and growth hormones. Evolution from a promordial peptide by gene duplication. Proc. Natl. Acad. Sci. USA 68, 866.

Nicoll CS, BERN HA. (1972) On the actions of prolactin among vertebrates: is there a common denominator? In: Wolstenholme GEW, Knight J, eds. Lactogenic Hormones. London: Churchill Livingstone, 299.

Okamura H, Zachwieja J, Raguet S, Kelly PA. (1989) Characterization and applications of monoclonal antibodies to the prolactin receptor. Endocrinol. 124, 2499.

RUI H, KIRKEN RA, FARRAR WL. (1994) A ctivation of receptor-associated tyrosine kinase JAK 2 by prolactin. J. Biol. Chem. 269, 5364.

Shirota M, BAnVille D, Ali S et al. (1990) Expression of two forms of prolactin receptor in rat ovary and liver. Mol. Endocrinol. 4, 1136.

Stevens A M, Yu-Lee LY. (1992) The transcription factor interferon regulatory factor-1 is expressed during both early $\mathrm{G} 1$ and $\mathrm{G} 1 / \mathrm{S}$ transition in the prolactin-induced lymphocyte cell cycle. Mol. Endocrinol. 6, 2236.

Sugiyama T, Minoura H, Kawabe N, Tanaka M, Nakashima K. (1994) Preferential expression of long form of prolactin receptor $\mathrm{mRNA}$ in the rat brain during the estrus cycle, pregnancy and lactation: hormones involved in its gene expression. J. Endocrinol. 141, 325.

Tanaka T, Shiu RPC, Gout PW, Beer CT, Noble RL, Friesen HG. (1980) A new sensitive and specific bioassay for lactogenic hormones: measurement of prolactin and growth hormone in human serum. J. Clin. Endocrinol. Metabl. 51, 1058.

Viseldi SM, Mastro AM. (1991) Prolactin-induced mitogenesis of lymphocytes from ovariectomized rats. Endocrinol. 129, 983.

VISELLI SM . (1992) Characterization of prolactin-induced lymphocyte proliferation. Submitted in partial fulfillment of requirements for the degree of PhD at Pennsylvania State U niversity.

VISELLI SM, M AStRo AM . (1993) Prolactin receptors are found on heterogenous subpopulations of rat splenocytes. Endocrinol. 132, 571.

Y U -LEE LY. (1990) Prolactin stimulates transcription of growth related genes in Nb2 T lymphoma cells. Mol. Cell. Endocrinol. 68, 21. 